\title{
Direct immunofluorescence (DFA) on HEP2 and R-Mix Too for Adenovirus detection
}

\author{
Maria Elena Terlizzi, Stefano Gambarino, Massimiliano Bergallo, Cristina Costa, \\ Francesca Sidoti, Sara Astegiano, Rossana Cavallo \\ SC Virologia U, AOU San Giovanni Battista di Torino (Molinette), Torino
}

Keywords: Adenovirus, Direct immunofluorescence

Immunofluorescenza diretta (DFA) su cellule HEP2 e R-Mix Too per la rilevazione degli Adenovirus

\section{INTRODUCTION}

Human adenoviruses (ADV) are nonenveloped, icosahedral viruses containing a single linear, double-stranded DNA genome.

ADV can cause different clinical syndromes in immunocompetent individuals. High incidence of adenoviral infections and a severe clinical impact were observed in the immunocompromised patients, in particular ADV has been associated with airway diseases (1).

One of the classical diagnostic tools for ADV detection in biological samples is represented by immunofluorescence.

Cell lines commonly used include human epithelial cells such as A549, HEP2, the latter most often (2). R-Mix Too are a mixed cell cultures, consisting of A549 and MDCK cells, useful to detect the presence of respiratory viruses in biological samples in 24-48 hours. The purpose of this study was to compare the detection of ADV by direct immunofluorescence on HEP 2 and RMix Too cells.

\section{MATERIALS AND METHODS}

Ten-fold dilutions of ADV from $10^{4} \mathrm{TCID}_{50} / 200 \mu \mathrm{l}$ to $10^{-2}$ TCID $_{50} / 200 \mu 1$ were used to infect both HEP2 and R-Mix Too shell vials (Diagnostic Hybrids).

Immunofluorescence was performed using 3 different antibody dilutions (1:40, 1:80 and 1:160) and results were analyzed 48, 72, 96 hours post infection for HEP2 cells and 24, 48 hours for RMix Too cells according to the manufacturer's instructions.

\section{RESULTS}

ADV positivity was observed up to $10^{-1}$ $\mathrm{TCID}_{50} / 200 \mu \mathrm{l}$ on HEP2 cells $(72 \mathrm{~h}$ post infection with 1:40 antibody dilution), with a sentitivity of $10^{\circ}$ TCID50/200 $\mu$ l. As regards R-Mix Too cells, ADV positivity was observed up to $10^{1} \mathrm{TCID}_{50} / 200 \mu \mathrm{l}(48 \mathrm{~h}$ post infection with 1:80 antibody dilution), with a sensitivity of $10^{2} \mathrm{TCID}_{50} / 200 \mu \mathrm{l}$.

\begin{tabular}{lcc}
\hline ADV detection & \multicolumn{2}{c}{ Cell Type } \\
\cline { 2 - 3 } & HEP2 & R-Mix \\
\hline Too LOD (Limit Of Detection: & & \\
TCID & & \\
So $200 \mu \mathrm{I})$ & $10^{-1}$ & $10^{1}$ \\
\hline Sensitivity (TCID $50 / 200 \mu \mathrm{I})$ & $10^{\circ}$ & $10^{2}$ \\
\hline Time post infection (hours) & 72 & 48 \\
\hline
\end{tabular}

\section{CONCLUSION}

The comparison among two different cellular substrates for the detection of ADV has showed a difference of two logarithms in terms of sensitivity. In fact HEP2 cells are resulted more suitable as the sentivity reaches $10^{2} \mathrm{TCID}_{50} / 200 \mu$ instead of $10^{\circ} \mathrm{TCID}_{50} / 200 \mu \mathrm{l}$ for R-Mix Too cells.

\section{BIBLIOGRAFIA}

1. Echavarria M. Adenoviruses in immunocompromised hosts. Clin Microbiol Rev 2008; 21: 704-15.

2. Lipson SM, Poshni IA, Ashley RL, Grady LJ, Ciamician Z, Teichberg S. Presumptive identification of common adenovirus serotypes by the development of differential cytopathic effects in the human lung carcinoma (A549) cell culture. FEMS Microbiol Lett $1993 ; 113,75-82$.

\section{Corresponding author: Maria Elena Terlizzi}

Via Santena 9 - Torino 10126

Tel.: +39(I I)6705630 - Fax: +39(I I)6705648

E-mail: mariaelena.terlizzi@unito.it 